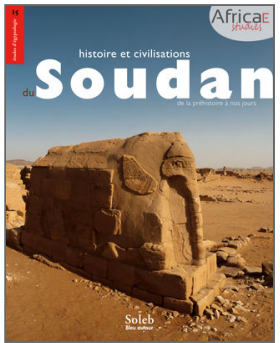

Histoire et civilisation du Soudan

De la préhistoire à nos jours

\title{
À nos amis
}

\section{Olivier Cabon}

DOI : 10.4000/books.africae. 3012

Éditeur : Africae, Soleb, Bleu autour

Lieu d'édition : Paris, Khartoum

Année d'édition : 2017

Date de mise en ligne : 17 janvier 2022

Collection : Africae Studies

EAN électronique : 9782493207074

\section{Q OpenEdition \\ Books}

http://books.openedition.org

\section{Référence électronique}

CABON, Olivier. À nos amis In : Histoire et civilisation du Soudan : De la préhistoire à nos jours [en ligne]

Paris, Khartoum : Africae, 2017 (généré le 28 janvier 2022). Disponible sur Internet : <http://

books.openedition.org/africae/3012>. ISBN : 9782493207074. DOI : https://doi.org/10.4000/

books.africae. 3012 


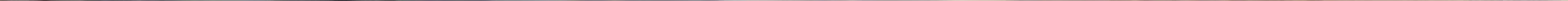




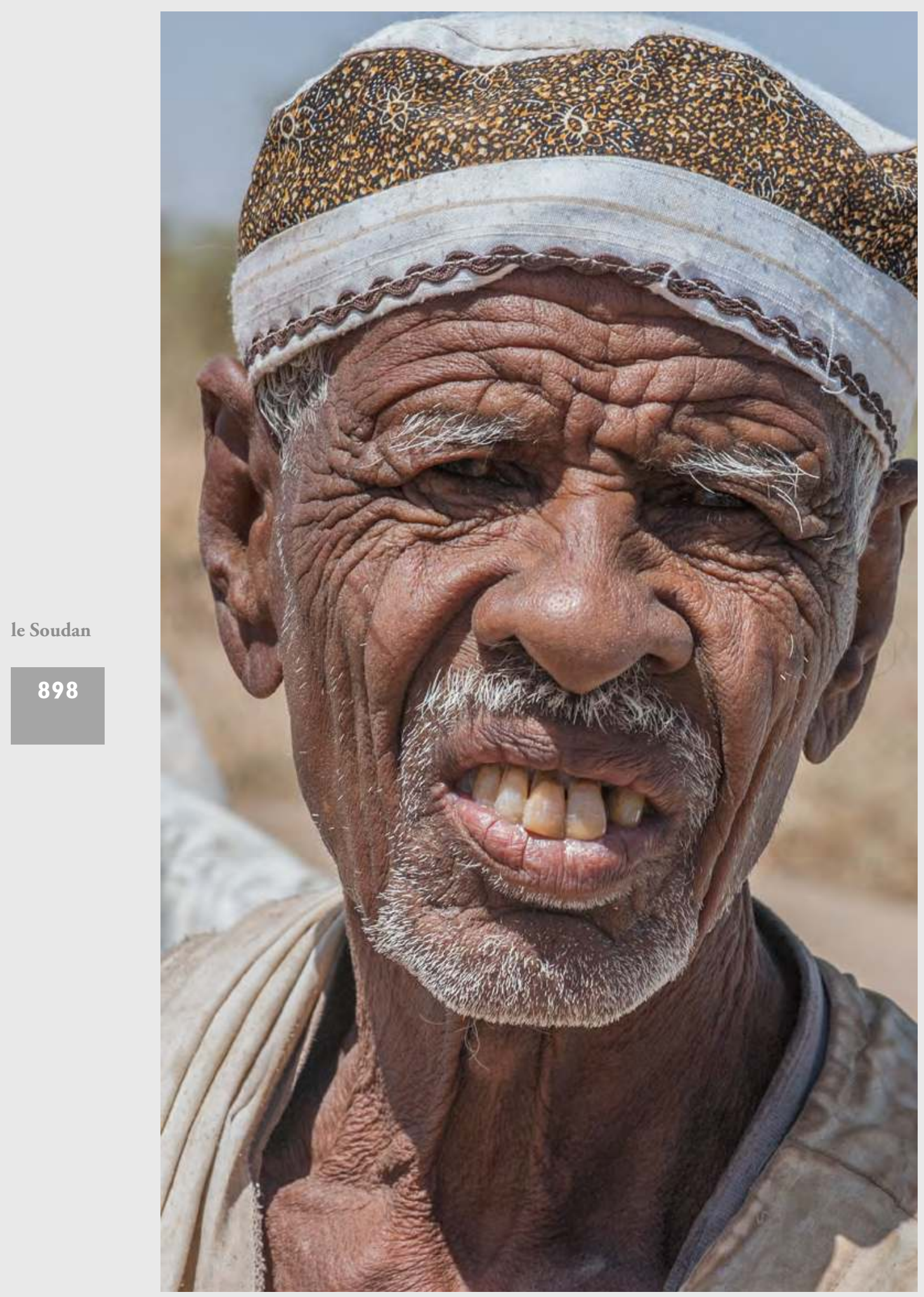

Hassan Zaki, Mouweis, 2011. 


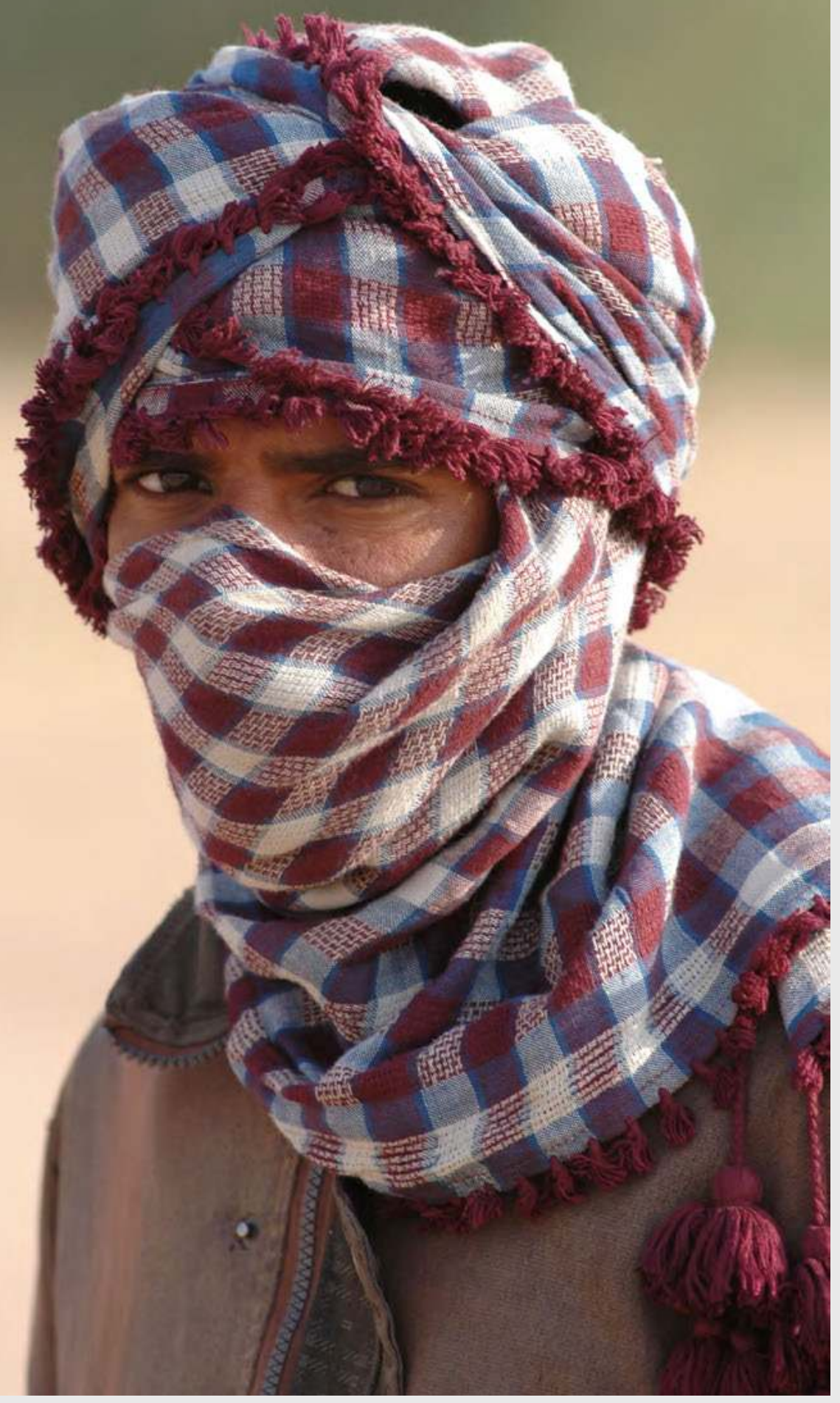



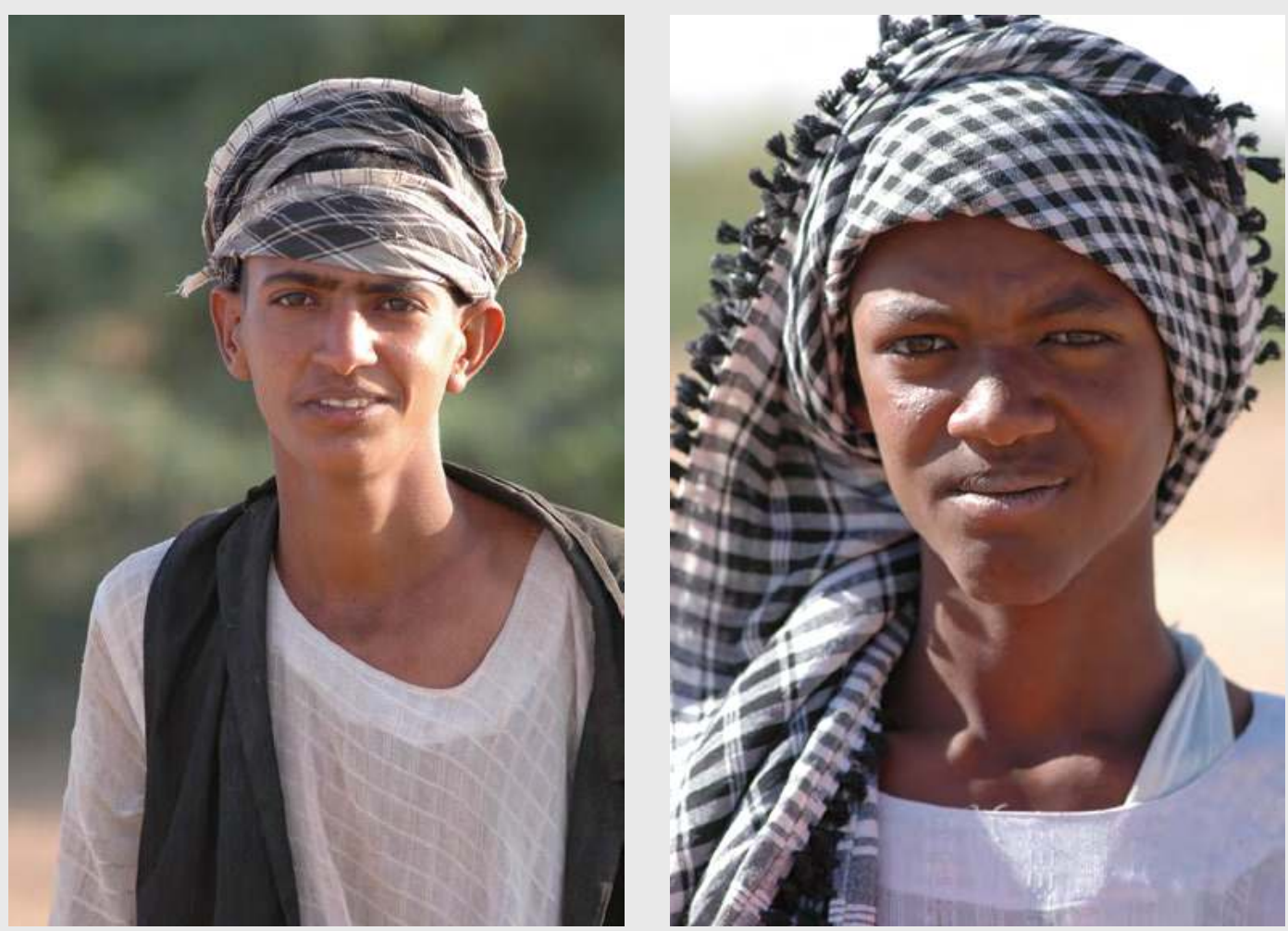

900
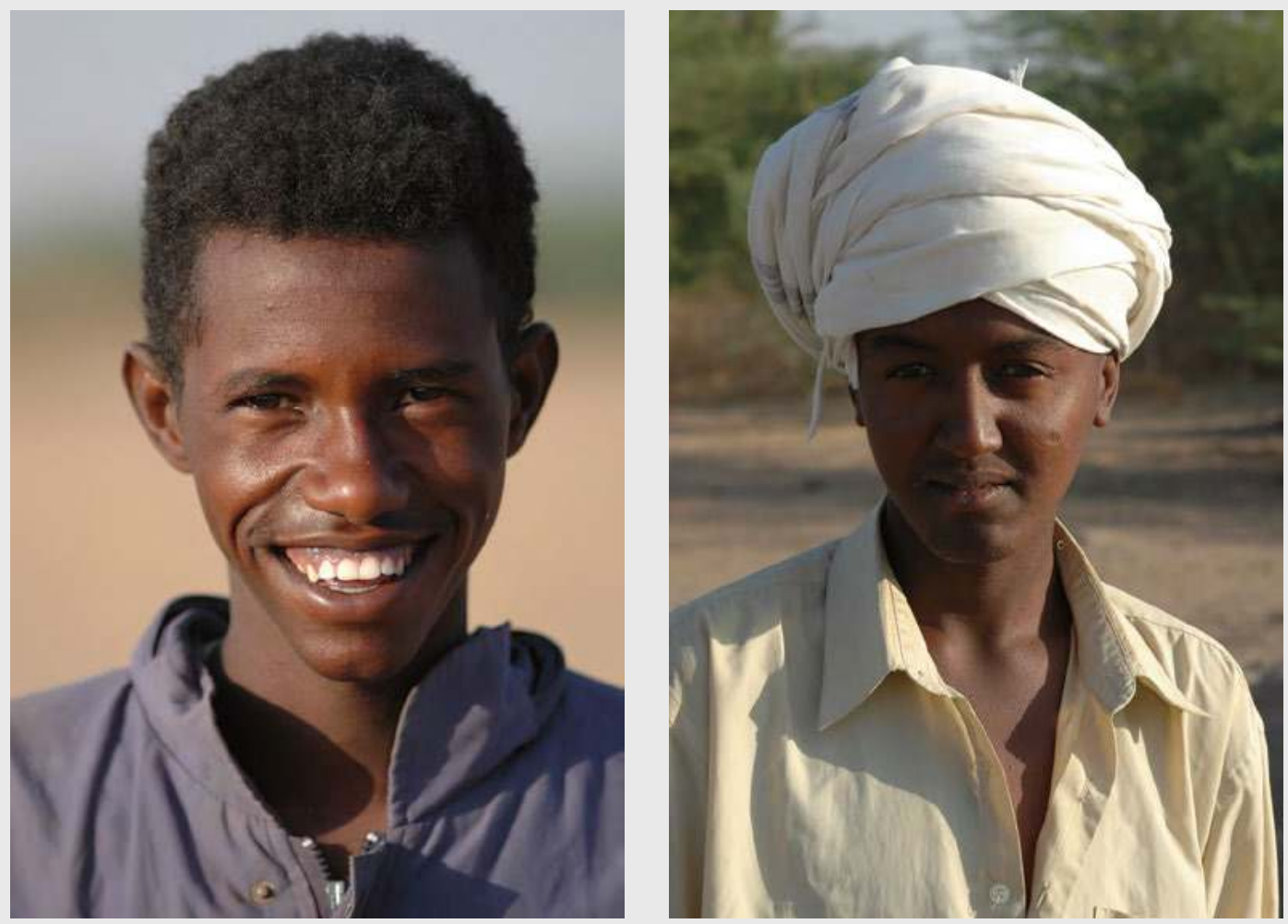

Hassan Louefy et Hafez (en haut), Mouweis, 2009 


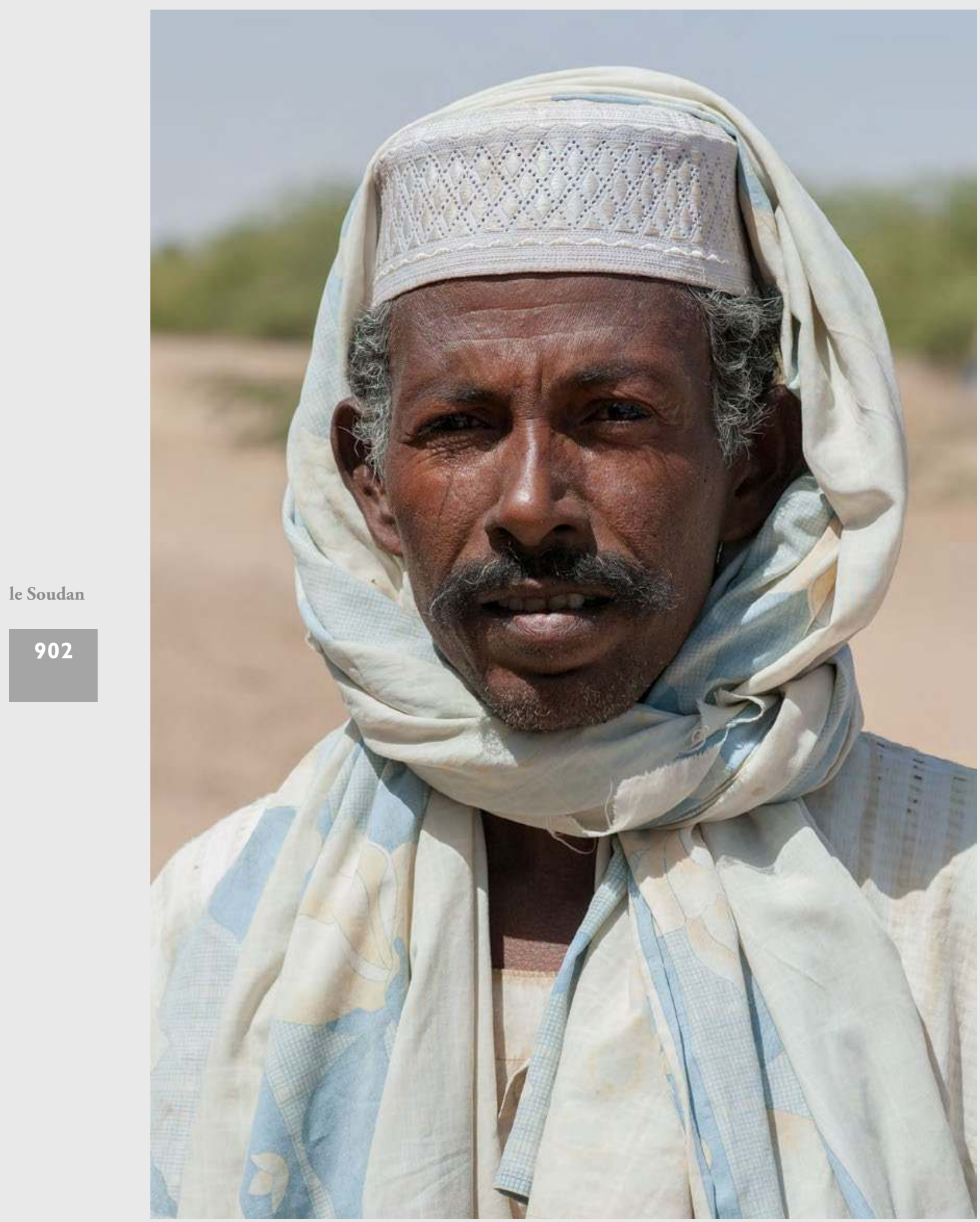

Salah Mohamed, Mouweis, 2011. 


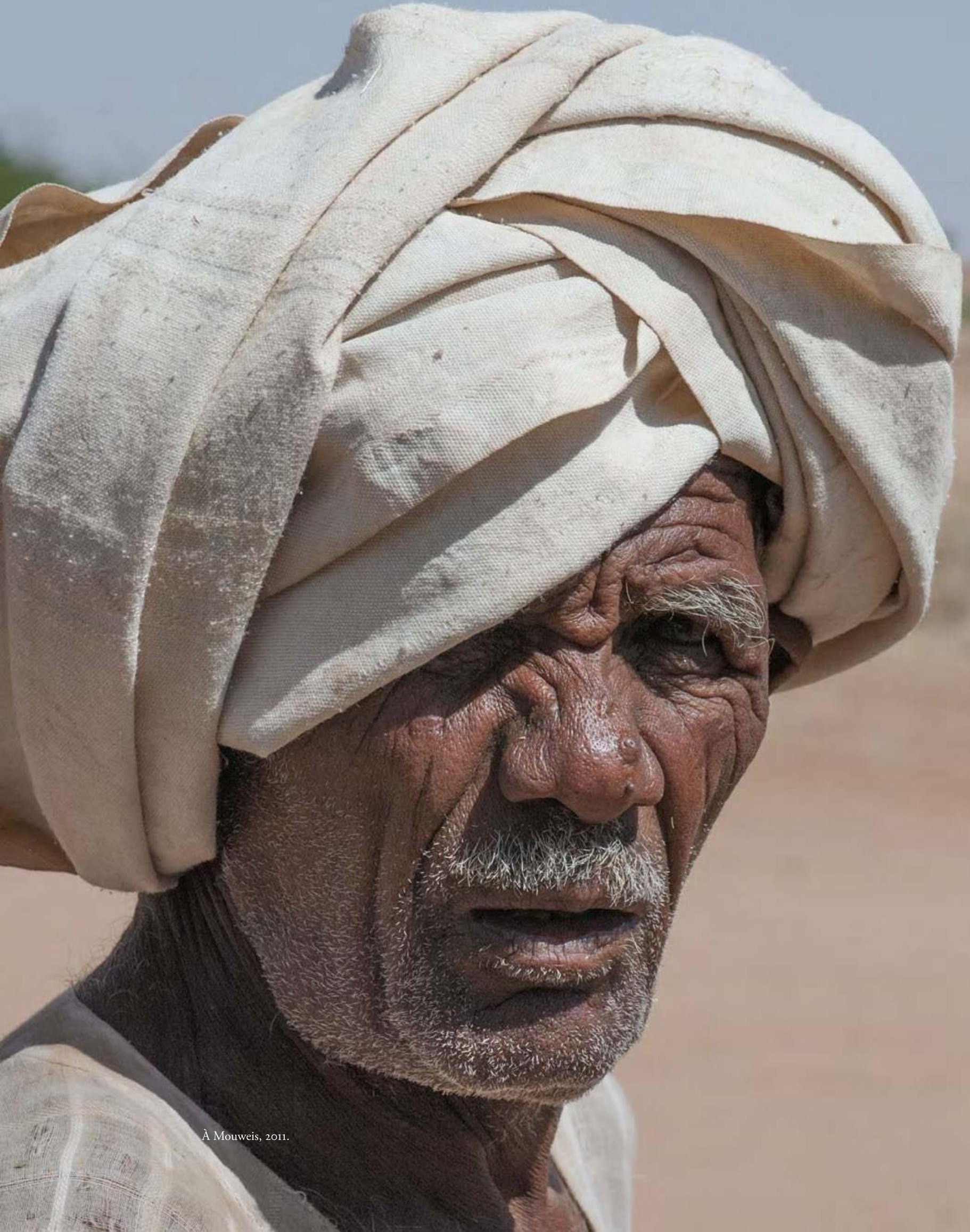



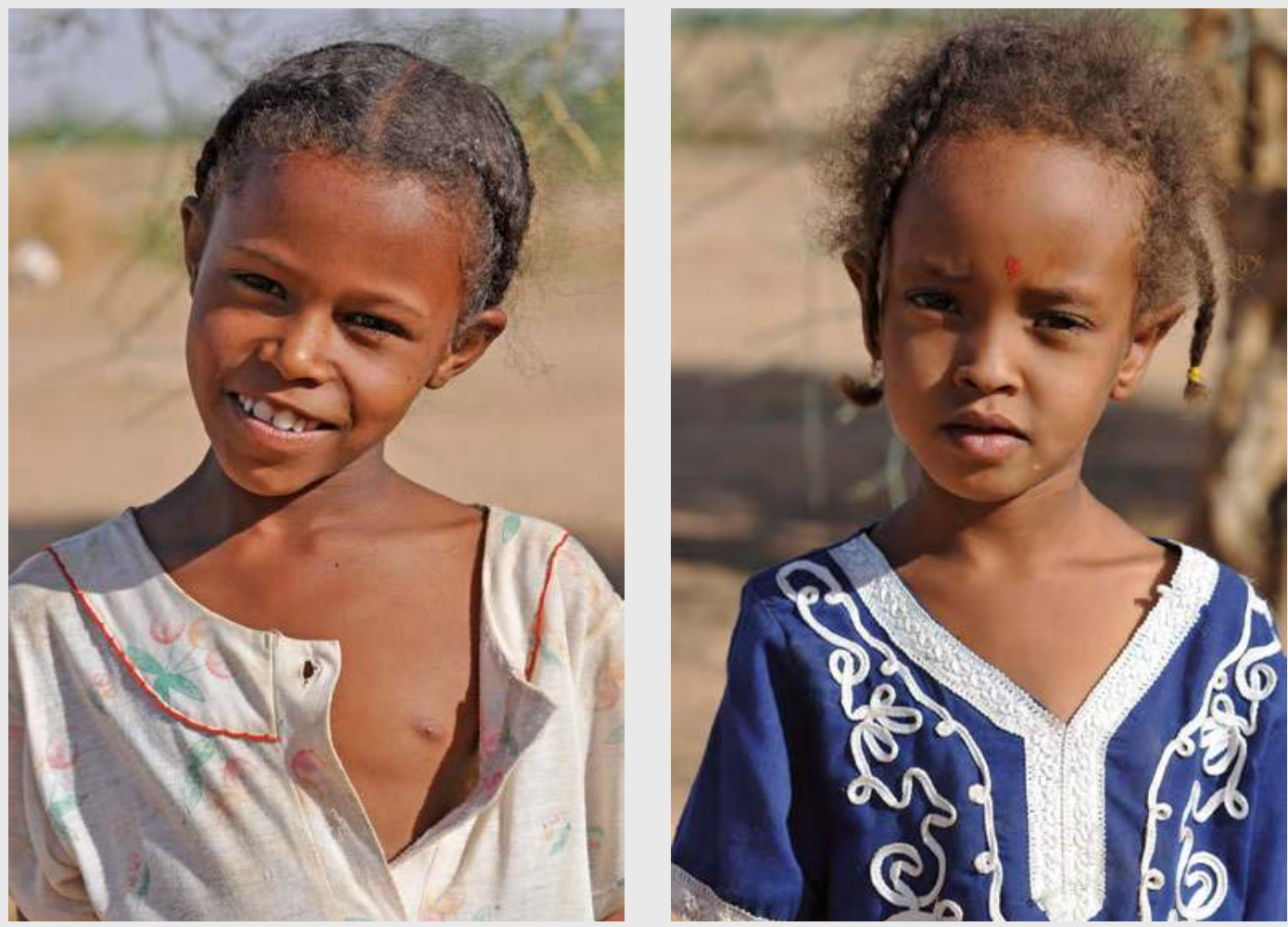

904
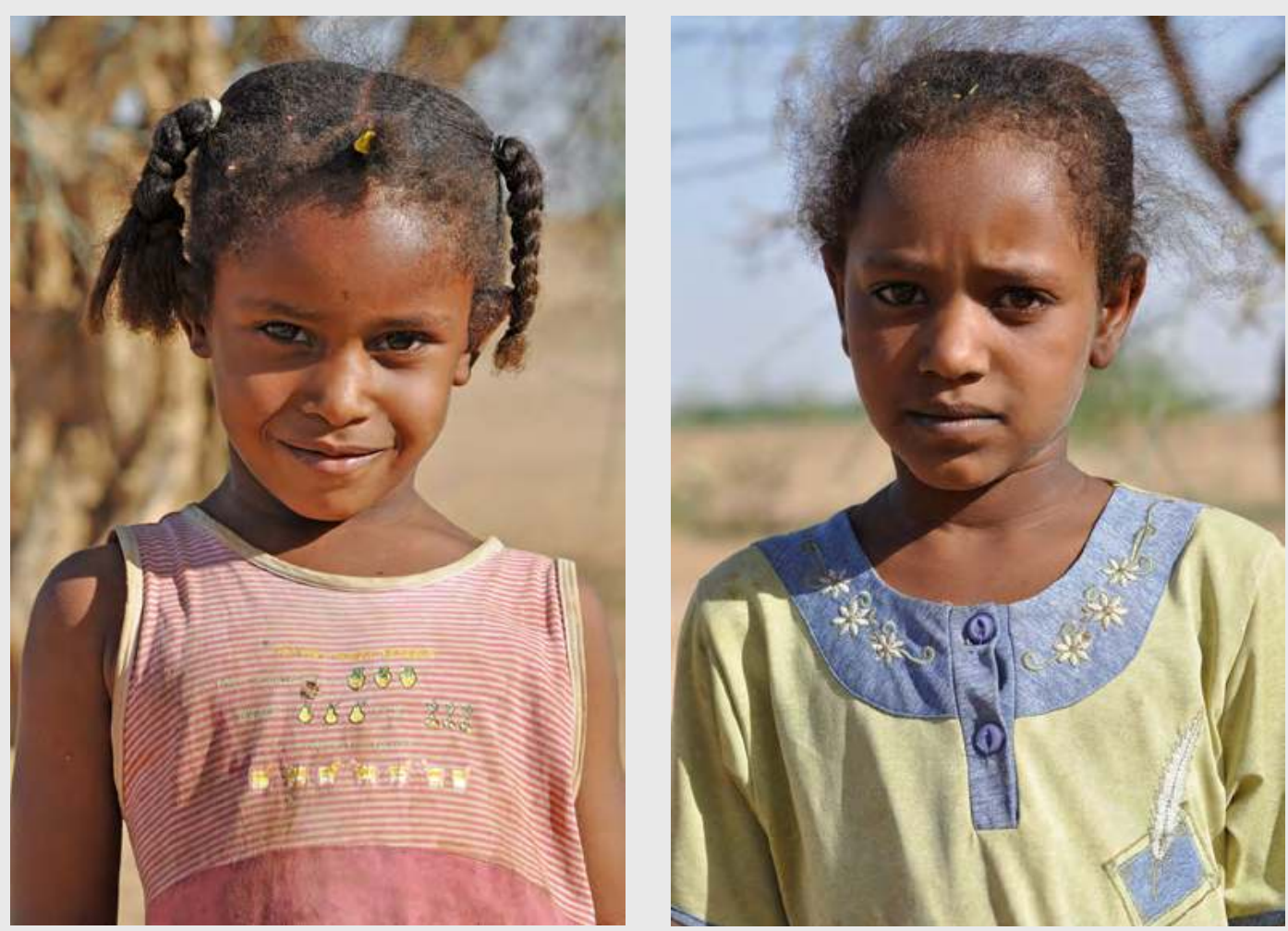

Les filles d'Abd el-Gadir, ghafir d'el-Hassa, 2010. 


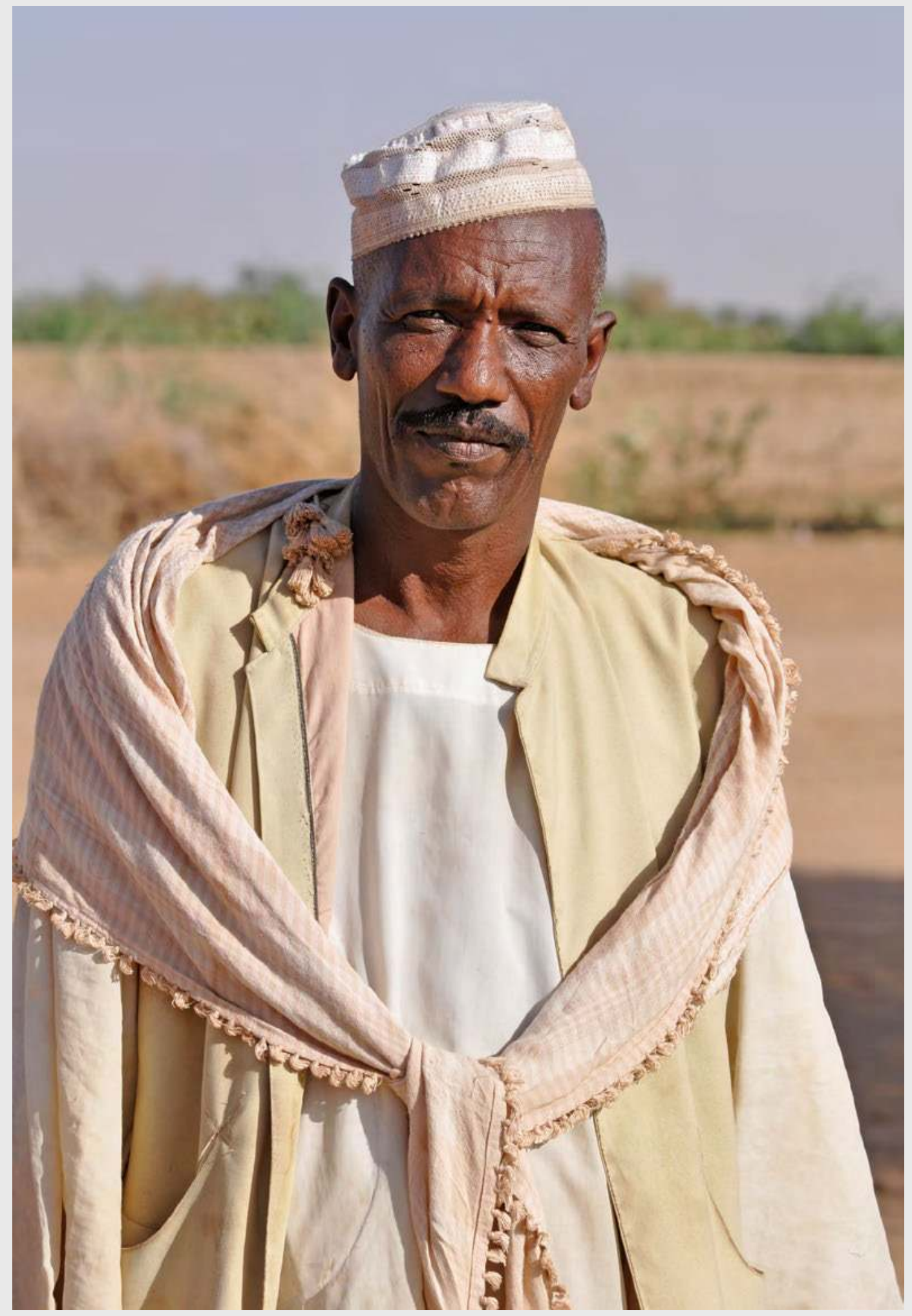

